\title{
Calcineurin expression and activity is regulated by the intracellular redox status and under hypertension in human neutrophils
}

\author{
Gonzalo Alba ${ }^{1, *}$, Consuelo Santa-María ${ }^{2, *}$, María Edith Reyes-Quiroz ${ }^{1}$, Rajaa El Bekay ${ }^{3}$, Isabel Geniz ${ }^{4}$, \\ José Martín-Nieto ${ }^{5}$, Elizabeth Pintado ${ }^{1}$ and Francisco Sobrino ${ }^{1,+}$ \\ ${ }^{1}$ Departamento de Bioquímica Médica y Biología Molecular, Facultad de Medicina and ${ }^{2}$ Departamento de Bioquímica y Biología Molecular, Universidad de \\ Sevilla, Avenida Sánchez Pizjuán 4, E-41009 Sevilla, Spain \\ ${ }^{3}$ CIBER in Physiopathology of Obesity and Nutrition (CB06/03), Instituto de Salud Carlos III, Spain, and Research Laboratory, IMABIS Foundation, \\ Virgen de la Victoria University Hospital, Málaga, Spain \\ ${ }^{4}$ Centro de Salud Guillena, Distrito Sanitario Sevilla Norte, Sevilla, Spain \\ ${ }^{5}$ Departamento de Fisiología, Genética y Microbiología, Universidad de Alicante, Alicante, Spain \\ (Correspondence should be addressed to F Sobrino; Email: fsobrino@us.es) \\ *(G Alba and C Santa-María contributed equally to this work) \\ ${ }^{\dagger}(\mathrm{F}$ Sobrino is a senior author $)$
}

\begin{abstract}
Calcineurin (protein phosphatase $2 \mathrm{~B})(\mathrm{CN})$ comprises a family of serine/threonine phosphatases that play a pivotal role in signal transduction cascades in a variety of cells, including neutrophils. Angiotensin II (Ang II) increases both activity and de novo synthesis of $\mathrm{CN}$ in human neutrophils. This study focuses on the role that intracellular redox status plays in the induction of $\mathrm{CN}$ activity by Ang II. Both de novo synthesis of $\mathrm{CN}$ and activity increase promoted by Ang II were downregulated when cells were treated with L-buthionine-(S,R)-sulfoximine, an inhibitor of synthesis of the antioxidant glutathione. We have also investigated the effect of pyrrolidine dithiocarbamate and phenazine methosulfate, which are antioxidant and oxidant compounds, respectively, and concluded that the intracellular redox status
\end{abstract}

of neutrophils is highly critical for Ang II-induced increase of $\mathrm{CN}$ expression and activity. Results obtained in neutrophils from hypertensive patients were very similar to those obtained in these cells on treatment with Ang II. We have also addressed the possible functional implication of $\mathrm{CN}$ activation in the development of hypertension. Present findings indicate that downregulation of hemoxygenase-1 expression in neutrophils from hypertensive subjects is likely mediated by $\mathrm{CN}$, which acts by hindering translocation to the nucleus of the transcription factor NRF2. These data support and extend our previous results and those from other authors on modulation of $\mathrm{CN}$ expression and activity levels by the intracellular redox status.

Journal of Endocrinology (2012) 214, 399-408

\section{Introduction}

Redox regulation of cellular processes is currently a focus of intense research (Finkel 2011). The intracellular redox status is determined by the balance between reactive oxygen species (ROS) and the cellular antioxidant defenses. Although high concentrations of ROS are catatonic, they are now known to function as signal transducing molecules at lower concentrations, modulating indirectly the activity of many enzymes and transcription factors. Classical regulation of the activity of these proteins by phosphorylation is subjected to modulation by ROS. In general, ROS increase net phosphorylation by inhibiting phosphatases and only some kinases can be directly modified by them (Paravicini \& Touyz 2006).

Calcineurin $(\mathrm{CN})$ is a $\mathrm{Ca}^{2+} /$ calmodulin-dependent serine/threonine phosphatase. Since its first proposed biological role as a putative inhibitor of calmodulin-dependent phosphodiesterase, $\mathrm{CN}$ has gradually revealed itself as a modulator of the immune response. $\mathrm{CN}$ is the main target of the immunosuppressive drugs cyclosporine A (CsA) and tacrolimus, and it is considered nowadays as a major player in $\mathrm{Ca}^{2+}$-dependent eukaryotic signal transduction pathways (Lawrence et al. 2011). In this context, $\mathrm{CN}$ regulates the expression of a number of immune-response genes through dephosphorylation of a family of transcription factors known as nuclear factors of activated T cells (NF-ATs; Rusnak \& Mertz 2000). CN belongs to the class of metallophosphatases containing iron and zinc in the binuclear center at their active site. During the past two decades, several studies have shed light on possible mechanisms of $\mathrm{CN}$ activity modulation by ROS. It has been described that superoxide is a very potent $\mathrm{CN}$-inhibiting species, acting by altering the redox state of iron at the CN active site (Namgaladze et al. 2002). Although $\mathrm{CN}$ function is particularly important in brain, cartilage, and 
lymphocytes, we have shown that neutrophils also exhibit high CN expression (Carballo et al. 1999). Neutrophils, in addition to their classically assigned role in host defense against microbial pathogens, play a key function in the genesis of inflammatory diseases through the release of ROS (Segel et al. 2011).

Hypertension is considered nowadays to be an inflammatory disease, and increasing knowledge on hypertension has led to appreciation of the relevant role in this process of circulating leukocytes in general, and of neutrophils in particular (Sela et al. 2004, Tsukimori et al. 2007). Angiotensin II (Ang II) is a potent vasoconstrictor and regulator of cellular immune responses through a $\mathrm{CN}$-dependent pathway (Nataraj et al. 1999).

Previous work from our group indicates that neutrophils are highly responsive to Ang II in the context of superoxide anion production and upregulation of $\mathrm{CN}$ activity and synthesis (El Bekay et al. 2003). In neutrophils from healthy and hypertensive subjects, we have reported that expression of the antioxidant enzyme hemoxygenase-1 (HO1 (HMOX1)) becomes induced at the mRNA and protein levels with a parallel increase in enzyme activity on treatment with prostaglandin (Alba et al. 2008). The present work focuses on the role that an altered intracellular redox status plays in the induction of $\mathrm{CN}$ activity. We have also investigated expression levels of $\mathrm{CN}$ in normal human neutrophils under treatment with Ang II, as well as in neutrophils from hypertensive patients, and we have analyzed the possible modulating role of $\mathrm{CN}$ in hypertension.

\section{Materials and Methods}

\section{Reagents}

Dextran T-500 and $\left[\gamma^{32} \mathrm{P}\right]$ ATP were obtained from Amersham Pharmacia Biotech. Ficoll-Paque was from BioWhittaker. CsA was kindly provided by Dr S F Borel (Sandoz Ltd., Basel, Switzerland). Glutathione (GSH), Ang II, L-buthionine-(S,R)-sulfoximine (BSX), diisopropyl fluorophosphate (DFP) soybean trypsin inhibitor, leupeptin, aprotinin, and goat antirabbit IgG conjugated to HRP were purchased from Sigma. The synthetic peptide used as a substrate for $\mathrm{CN}$ was purchased from Peninsula Laboratories. 2-Mercaptoethanol, SDS, acrylamide, $N, N^{\prime}$-methylenebisacrylamide, and blotting polyvinylidene difluoride (PVDF) transfer membranes were purchased from Bio-Rad. Rabbit antibovine CN IgG was kindly provided by C B Klee (National Institutes of Health, Bethesda, MD, USA). Antibodies to HO1 (sc-10789) and Nrf2 (sc-722) were from Santa Cruz Biotechnology (Santa Cruz, CA, USA).

\section{Isolation and culture of human neutrophils}

Human peripheral blood neutrophils were isolated from fresh heparinized blood of human donors by dextran sedimentation

followed by Ficoll-Paque gradient centrifugation, and hypotonic lysis of residual erythrocytes (Carballo et al. 1999). Neutrophils were washed twice in Hank's balanced salt solution and then suspended at a density of $10^{7}$ cells $/ \mathrm{ml}$ in RPMI 1640 medium supplemented with 10\% FCS plus gentamicin, penicillin, and streptomycin at $50 \mathrm{mg} / \mathrm{ml}$ each. Before all stimulations, neutrophil suspensions were preincubated at room temperature with $1 \mathrm{mM} \mathrm{DFP}$ (to minimize proteolysis) for $5 \mathrm{~min}$ (Gilbert et al. 2002). Neutrophils were incubated at $37^{\circ} \mathrm{C}$ for the times indicated in each experiment. Under these conditions, the cells, viability ranged between 90 and $97 \%$, as estimated by the lactic dehydrogenase release assay (Gualberto et al. 1998).

\section{Subjects}

Patients were eligible as hypertensive if they were $>18$ years old, suffered from moderate-to-high hypertension (systolic blood pressure, $>140 \mathrm{mmHg}$; diastolic blood pressure, $>90 \mathrm{mmHg}$; both measured for $24 \mathrm{~h}$ of Holter monitoring during unrestricted daily life), and they had not undergone any previous treatment with antihypertensive drugs or other compounds. Patients with diabetes mellitus, fasting glucose in serum $>120 \mathrm{mg} / \mathrm{dl}$, total cholesterol levels $>240 \mathrm{mg} / \mathrm{dl}$, or other pathologies were excluded. The criteria for normotensive subjects were to bear systolic and diastolic blood pressure values, $<120$ and $<80 \mathrm{mmHg}$ respectively. The general characteristics of all subjects used in this work are shown in Table 1. The Universidad de Sevilla Ethics Committee approved this study, and each subject gave informed consent before its undertaking.

\section{CN activity assay}

$\mathrm{CN}$ activity was measured as described previously (Carballo et al. 1999). Briefly, neutrophils $\left(1 \times 10^{7} \mathrm{cells} / \mathrm{ml}\right)$ were incubated in Krebs-Ringer-HEPES buffer (KR-HEPES) containing $118 \mathrm{mM} \mathrm{NaCl}, 4.75 \mathrm{mM} \mathrm{KCl}, 1.18 \mathrm{mM} \mathrm{H}_{2} \mathrm{PO}_{4}$, $1.18 \mathrm{mM} \mathrm{MgSO}_{4}, 1.25 \mathrm{mM} \mathrm{CaCl}_{2}, 10 \mathrm{mM}$ glucose, and $25 \mathrm{mM}$ HEPES ( $\mathrm{pH} 7 \cdot 4$ ), in the presence or absence of the drugs as indicated in the text. After incubation, the cells were

Table 1 General characteristics of normotensive and hypertensive subjects

Sex

Age (years)

Weight $(\mathrm{kg})$

Systolic blood pressure $(\mathrm{mmHg})$

Diastolic blood pressure $(\mathrm{mmHg})$

Body mass index $\left(\mathrm{kg} / \mathrm{m}^{2}\right)$

\begin{tabular}{|c|c|c|}
\hline Normotensives & Hypertensives & $P$ value \\
\hline $\begin{array}{l}\text { Five men; } \\
\text { five women }\end{array}$ & $\begin{array}{l}\text { Five men; } \\
\text { five women }\end{array}$ & \\
\hline $40-50$ & $40-50$ & NS \\
\hline $70 \cdot 2 \pm 3 \cdot 4$ & $83 \cdot 6 \pm 4 \cdot 3$ & NS \\
\hline $119 \cdot 3 \pm 6 \cdot 3$ & $170 \cdot 1 \pm 14 \cdot 0$ & $\leq 0 \cdot 001$ \\
\hline $75 \cdot 5 \pm 4 \cdot 5$ & $101 \cdot 4 \pm 7 \cdot 9$ & $\leq 0 \cdot 001$ \\
\hline $24 \cdot 2 \pm 3 \cdot 4$ & $28 \cdot 9 \pm 2 \cdot 2$ & $\leq 0.05$ \\
\hline
\end{tabular}


harvested and lysed on ice in $60 \mu \mathrm{l}$ of lysis buffer $(50 \mathrm{mM}$ Tris- $\mathrm{HCl} \mathrm{pH}$ 7·5, $1 \mathrm{mM}$ EDTA, 0.1 mM EGTA, 1\% Triton $\mathrm{X}-100,0.5 \mathrm{mM}$ dithiothreitol (DTT), $50 \mu \mathrm{g} / \mathrm{ml}$ soybean trypsin inhibitor, $50 \mu \mathrm{g} / \mathrm{ml}$ phenylmethylsulphonyl fluoride, $10 \mu \mathrm{g} / \mathrm{ml}$ leupeptin, and $10 \mu \mathrm{g} / \mathrm{ml}$ aprotinin). A reaction mixture containing $2 \mu \mathrm{M}{ }^{32} \mathrm{P}$-labeled phosphopeptide, $500 \mathrm{nM}$ okadaic acid (added to inhibit PP-1 and PP-2 type phosphatases), $150 \mu \mathrm{M}$ trifluoperazine, and $50 \mu \mathrm{g}$ cell lysate protein were incubated in a total volume of $60 \mu \mathrm{l}$ of assay buffer $(20 \mathrm{mM}$ Tris- $\mathrm{HCl} \mathrm{pH} 7 \cdot 5,100 \mathrm{mM} \mathrm{NaCl}$, $6 \mathrm{mM} \mathrm{MgCl}_{2}, 0.5 \mathrm{mM} \mathrm{DTT} 0.1 \mathrm{mM} \mathrm{CaCl}_{2}$, and $0.1 \mathrm{mg} / \mathrm{ml}$ BSA) for $15 \mathrm{~min}$ at $30^{\circ} \mathrm{C}$. Subsequently, the reaction was stopped by the addition of $0.5 \mathrm{ml}$ of $100 \mathrm{mM}$ potassium buffer, $\mathrm{pH} 7 \cdot 0$, containing $5 \%$ trichloroacetic acid. The reaction mixture was passed through a $500 \mu \mathrm{l}$ column of activated Dowex cation-exchange resin, and free inorganic phosphate was quantitated in the eluate by scintillation counting. Data are expressed as the number of picomoles of ${ }^{32} \mathrm{PO}_{4}$ released in $15 \mathrm{~min} / \mathrm{mg}$ protein.

\section{GSH determination}

Neutrophils were lysed in $315 \mu$ of the phosphate-EDTA buffer containing $100 \mathrm{mM}$ sodium phosphate $(\mathrm{pH} \mathrm{8.0)}$ and $5 \mathrm{mM}$ EDTA, and $85 \mu \mathrm{l}$ of $25 \% \mathrm{HPO}_{3}$, which was used as a protein precipitant. The total homogenate was centrifuged at $4{ }^{\circ} \mathrm{C}$ at $100000 \mathrm{~g}$ for $30 \mathrm{~min}$ to obtain the supernatant for the assay of GSH. This was performed by a modification of the method of Hissin \& Hilf (1976). To $100 \mu$ l of the $100000 \mathrm{~g}$ supernatant, $565 \mu \mathrm{l}$ Tris-HCl-EDTA buffer, containing $200 \mathrm{mM}$ Tris- $\mathrm{HCl} \mathrm{pH} 8 \cdot 2$ and $5 \mathrm{mM}$ EDTA, was added together with $35 \mu \mathrm{l}$ of $1 \mathrm{mg} / \mathrm{ml} \mathrm{O}$-phthalaldehyde in $100 \%$ methanol. After thorough mixing and incubation at room temperature for $15 \mathrm{~min}$, the solution was transferred to a quartz cuvette. Fluorescence at $420 \mathrm{~nm}$ was determined at an activation wavelength of $350 \mathrm{~nm}$.

\section{Western blotting analysis of CN, HO1, and NRF2 protein levels}

Total cell lysates and nuclear extracts were prepared basically as described (Carballo et al. 1999). Western blotting analysis of HO1 (HMOX1) protein levels was performed on total cell lysates as described (Alvarez-Maqueda et al. 2004). To verify even protein loading, the blots were subsequently stripped and reprobed with polyclonal antibodies against GAPDH at a 1:1000 dilution. Blots were probed with rabbit polyclonal antibodies to HO1 at a 1:1000 dilution. NRF2 levels were analyzed on nuclear extracts by using the anti-Nrf2 IgG at a 1:5000 dilution. CN levels were measured using rabbit antibovine $\mathrm{CN} \operatorname{IgG}$ at a 1:1000 dilution. Band intensities were quantitated densitometrically using the Scion Image software (Scion, Inc., Frederick, MD, USA) and corrected for differences in GAPDH levels, in the case of HO1 and CN, and for differences in nuclear proteins stained with Ponceau Red, in the case of NRF2.

\section{HO1 mRNA levels}

Total cellular RNA extraction and reverse transcription into cDNA were performed as described previously (Alvarez-Maqueda et al. 2004). Real-time PCR analysis of HO1 mRNA levels was performed using the ABI Prism 7300 sequence detection system from Applied Biosystems, under specific thermocycling conditions according to the primers used. PCRs were performed in triplicate. Each sample was also analyzed for GAPDH transcript levels to normalize for RNA input amounts. For the relative quantification of gene expression, the comparative threshold cycle method was used as described in the ABI Prism 7700 User Bulletin 2.

\section{Glutathione peroxidase and GSH reductase activities}

Glutathione peroxidase (GPx) activity was assayed with a coupled enzyme system in which oxidized glutathione (GSSG) reduction was coupled to NADPH oxidation by glutathione reductase (GR; Lawrence \& Burk 1976). GR activity was determined spectrophotometrically by measuring NADPH oxidation at $340 \mathrm{~nm}$ (Carlberg \& Mannervik 1975). All measurements were carried out in a Shimadzu 160A ultraviolet spectrophotometer using $1 \mathrm{ml}$ cuvettes of $1 \mathrm{~cm}$ light path.

\section{Statistical analysis}

Protein expression levels are expressed in arbitrary units as the mean \pm s.E.M. from a minimum number of three independent experiments. The data were subjected to ANOVA and to the Student's paired $t$-test using the Statgraphics Plus 5.0 software (Manugistic Inc., Rockville, MD, USA).

\section{Results}

Effect of Ang II and intracellular GSH levels on the induction of CN activity in human neutrophils

In a previous work, we have evidenced that Ang II increases ROS production with an associated activation of MAPK. Besides, we found that Ang II increases both activity and de novo synthesis of $\mathrm{CN}$ in human neutrophils with a maximum stimulation being obtained at a $100 \mathrm{nM}$ concentration of this hormone (El Bekay et al. 2003). Experiments in this work were thus addressed to analyze whether the increase of $\mathrm{CN}$ synthesis and activity promoted by Ang II in neutrophils was modulated by the intracellular redox state. Given that reduced GSH plays an important role in control of the latter, neutrophils were treated with BSX, a specific inhibitor of $\gamma$-glutamylcysteine synthase (Cuzzocrea et al. 1998), in order to depress GSH levels.

Figure 1 illustrates $\mathrm{CN}$ activity levels measured in neutrophils previously incubated with 10 or $20 \mu \mathrm{M}$ BSX 


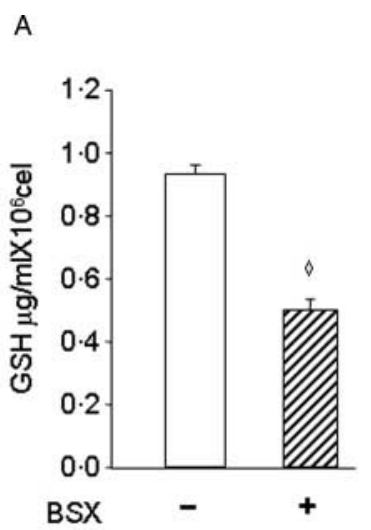

C

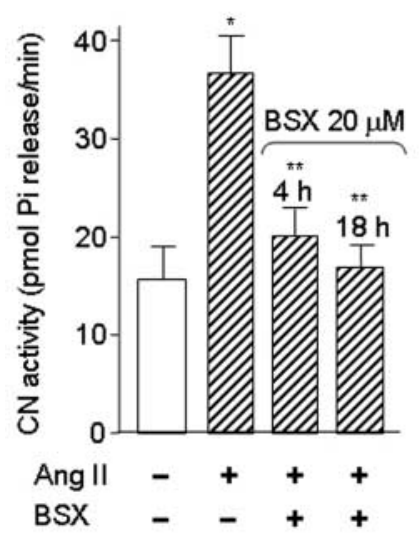

B

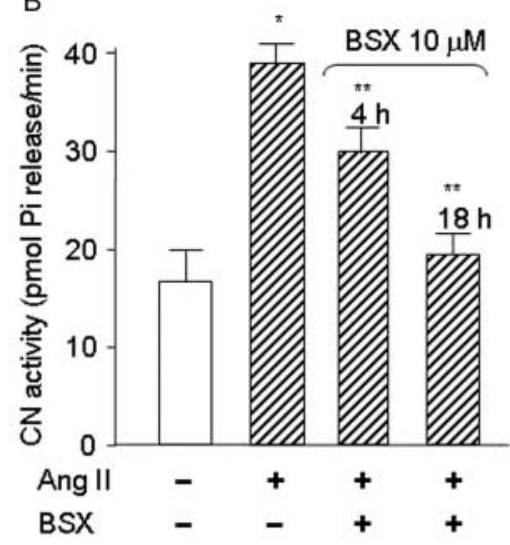

D

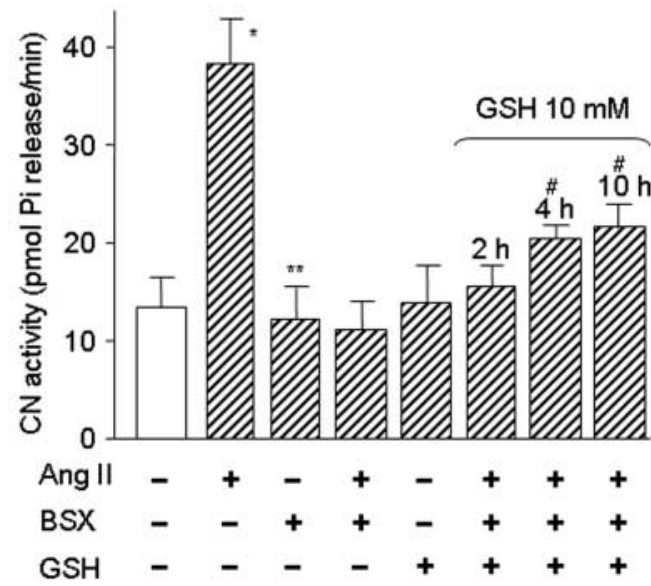

Figure 1 Depletion of endogenous GSH on treatment with BSX inhibits Ang Il-induced CN activation in human neutrophils. Neutrophils $\left(6 \times 10^{6} \mathrm{cell} / \mathrm{s} / \mathrm{ml}\right)$ were incubated either alone or in the presence of BSX at $10 \mu \mathrm{M}$ (B) or $20 \mu \mathrm{M}$ (A and C) for 4 (A) or 4 or $18 \mathrm{~h}$ (B and C) at $37^{\circ} \mathrm{C}$, as indicated. Further, the cells were incubated in the absence or presence of $100 \mathrm{nM}$ Ang II for $5 \mathrm{~h}$. Some cell preparations were incubated in the presence of $10 \mathrm{mM} \mathrm{GSH}$ for 2, 4, or $10 \mathrm{~h}$ (D). A control including $100 \mathrm{nM}$ Ang II or BSX is shown. The cells were lysed and GSH levels or $\mathrm{CN}$ activity was assayed as described in Materials and Methods section. Results are expressed as picomoles of Pi released/min. Mean \pm S.E.M. values from three separate experiments each performed in triplicate are presented. Statistical significance: $\diamond P<0 \cdot 001$, for BSX-treated vs BSX-untreated, $* P<0 \cdot 001$, for Ang II-treated vs Ang II-untreated; ${ }^{* *} P<0 \cdot 01$, for BSX- and Ang II-treated vs Ang II-treated and BSX-untreated. ${ }^{\sharp} P<0 \cdot 01$, for Ang II-, BSX-, and GSH-treated vs Ang II- and BSX-treated and GSH-untreated.

and subsequently treated with $100 \mathrm{nM}$ Ang II. We previously tested that BSX effectively depressed GSH content in neutrophils (Fig. 1A). Treatment with this inhibitor resulted in a time-dependent loss of the ability of Ang II to enhance $\mathrm{CN}$ activity, this returning to basal levels (i.e. those found in the absence of Ang II) after $18 \mathrm{~h}$ of incubation in the presence of BSX (Fig. 1B and C). However, no in vitro effect of BSX alone was found on $\mathrm{CN}$ activity (Fig. 1D). Figure 1D illustrates that the addition of GSH to these cells was able to reverse the inhibitory effect elicited by prior BSX treatment on Ang II-mediated increase of CN activity. As shown, after $4 \mathrm{~h}$ of treatment with $10 \mathrm{mM}$ GSH, CN activity was increased twofold by Ang II, even in the presence of BSX. By contrast, GSH addition was unable to enhance by itself Ang II-dependent CN induction.

In a previous work, we found that Ang II treatment induced the synthesis of a new CN protein (El Bekay et al. 2003). Here we have studied the effect of GSH depletion on Ang II-induced CN synthesis. With this purpose, we used a $\mathrm{CN}$ antibody, prepared from bovine $\mathrm{CN}$, which for a long time has shown a very good reactivity to human CN (Aperia et al. 1992). By using immunological methods, we observed that the levels of both CN subunits, 19 and $59 \mathrm{kDa}$, were clearly increased $5 \mathrm{~h}$ after Ang II addition to neutrophils

www.endocrinology-journals.org 

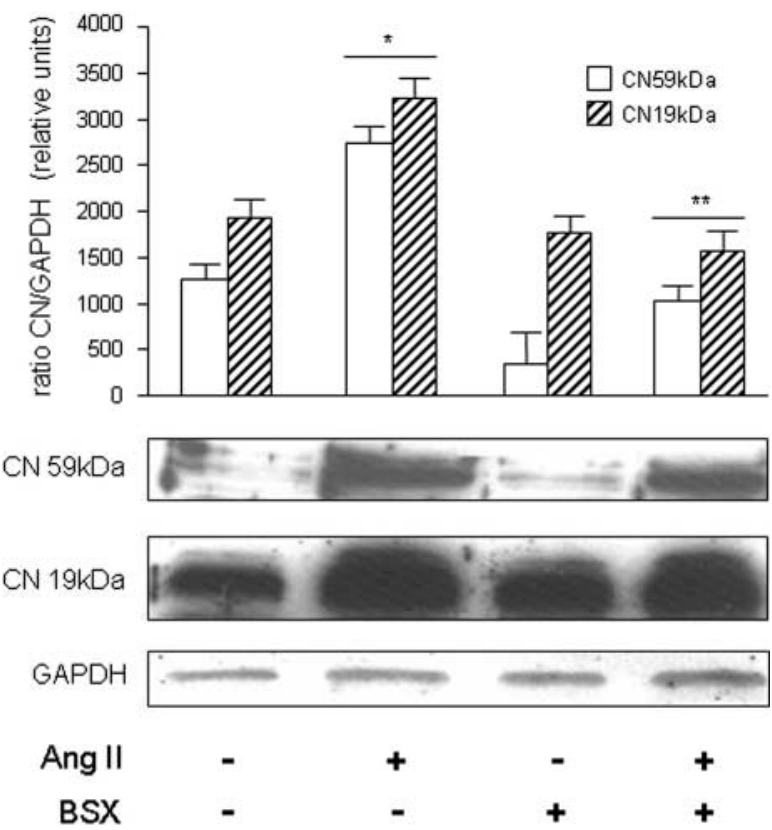

Figure 2 Depletion of GSH prevents Ang Il-induced CN synthesis in human neutrophils. Neutrophils $\left(10^{7} \mathrm{cell} / \mathrm{s} / \mathrm{ml}\right)$ were incubated either alone or in the presence of BSX at $20 \mu \mathrm{M}$ for $18 \mathrm{~h}$, and then Ang II was added at $100 \mathrm{nM}$ where indicated for a further $5 \mathrm{~h}$. Untreated cells were used as controls. The cells were lysed and proteins were resolved by SDS-PAGE, transferred to a PVDF membrane, and probed with a polyclonal antiserum against the A (59 kDa) and B (19 kDa) chains of $\mathrm{CN}$. The bands shown are representative of a set of three independent experiments. Plotted values (mean \pm S.E.M.) represent $\mathrm{CN}$ protein levels corrected for differences in GAPDH levels. Statistical significance: $* P<0 \cdot 01$, for Ang II-treated vs Ang II-untreated; ${ }^{* *} P<0 \cdot 01$, for BSX- and Ang II-treated vs Ang II-treated and BSX-untreated.

(Fig. 2). It was also noticeable that Ang II-dependent de novo $\mathrm{CN}$ synthesis was decreased when the neutrophils were treated with $20 \mu \mathrm{M}$ BSX for $20 \mathrm{~h}$, but that the amount of CN protein was higher than that found in untreated cells. This fact was in contrast with the observation that BSX decreased CN activity down to basal levels, which could indirectly suggest a positive role of GSH on the catalytic center of CN (Fig. 1B).

In a new series of experiments, we analyzed whether environmental stress induced by other specific redox reagents, added to neutrophils a short time (ca. $1 \mathrm{~h}$ ) before Ang II, could modify Ang II-dependent CN activation. First, we assayed the thiol-containing antioxidant, pyrrolidine dithiocarbamate (PDTC), and the effect we observed was opposite to that obtained with GSH, in the sense that $\mathrm{CN}$ activity was completely abolished after $1 \mathrm{~h}$ of treatment with PDTC (Fig. 3). Next, we incubated cells with an oxidant compound, phenazine methosulfate (PMS). It was found that PMS also prevented induction of $\mathrm{CN}$ activity by Ang II, although to a lesser extent than did PDTC (Fig. 3). These data taken together indicated that the intracellular redox status of neutrophils was highly critical for Ang II-mediated induction of $\mathrm{CN}$ activity.
Effect of hypertension on the induction of $\mathrm{CN}$ activity in human neutrophils

Hypertension is characterized by high intrarenal levels of Ang II (Navar et al. 2011). Thus, subsequent experiments using this hormone were carried out in human neutrophils from hypertensive patients compared with cells from healthy subjects. As shown in Fig. 4, neutrophils from hypertensive patients exhibited an increased basal expression of $\mathrm{CN}$ with respect to normotensive neutrophils. These high levels of $\mathrm{CN}$ decreased when neutrophils from hypertensive patients were incubated at $37^{\circ} \mathrm{C}$ for $15 \mathrm{~h}$ in the absence, but not in the presence, of $100 \mathrm{nM}$ Ang II. The results obtained in human neutrophils incubated with Ang II were thus very similar to those obtained in untreated neutrophils from hypertensive patients.

\section{GSH-related enzyme levels in neutrophils from hypertensive patients}

Taking into account the importance of GSH in modulation of CN activity, we studied the activity of GPx and GR, two enzymes responsible for intracellular levels of GSH in human neutrophils. The activity data obtained in hypertensive patients were normalized to those found in normotensive subjects and are shown in Fig. 5. It was observed that levels of GPx activity were ca. $22 \%$ lower in neutrophils from hypertensive patients than from healthy subjects $(P<0 \cdot 001)$. By contrast, GR activity underwent a slight, but not significant, decrease in neutrophils from hypertensive patients compared with normotensive ones.

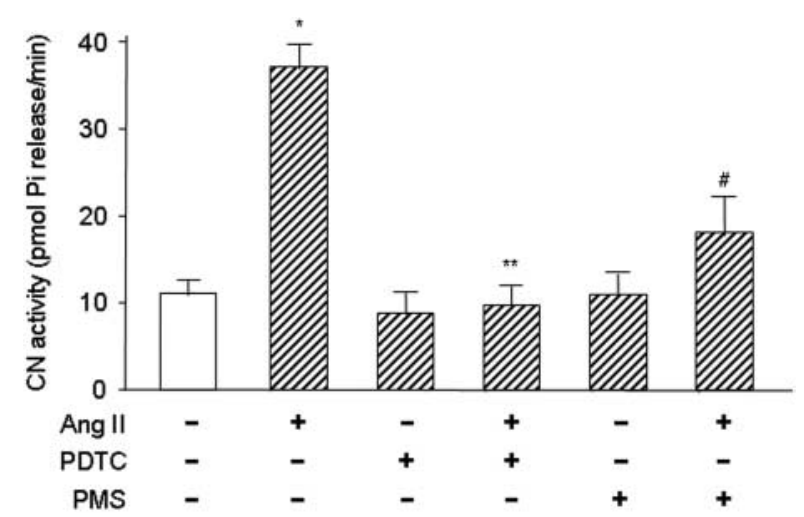

Figure 3 Effects of PDTC and PMS on Ang II-induced CN activation in human neutrophils. Neutrophils $\left(6 \times 10^{6} \mathrm{cells} / \mathrm{ml}\right)$ were incubated either alone or in the presence of PDTC $(100 \mu \mathrm{M})$ for $1 \mathrm{~h}$ at $37{ }^{\circ} \mathrm{C}$ or with PMS $(10 \mu \mathrm{M})$ for $30 \mathrm{~min}$. Further, the cells were incubated for $5 \mathrm{~h}$ in the presence of Ang II (100 $\mathrm{nM})$ where indicated. The cells were then lysed and $\mathrm{CN}$ activity was measured. Results are expressed as picomoles of Pi released/min. Mean \pm s.E.M. values from three separate experiments each performed in triplicate are presented. Statistical significance: ${ }^{*} P<0 \cdot 001$, for Ang II-treated vs Ang II-untreated; $* * P<0 \cdot 001$, for PDTC- and Ang II-treated vs Ang-treated; ${ }^{\#} P<0 \cdot 01$, for PMS- and Ang II-treated vs PMS-treated and Ang-untreated. 


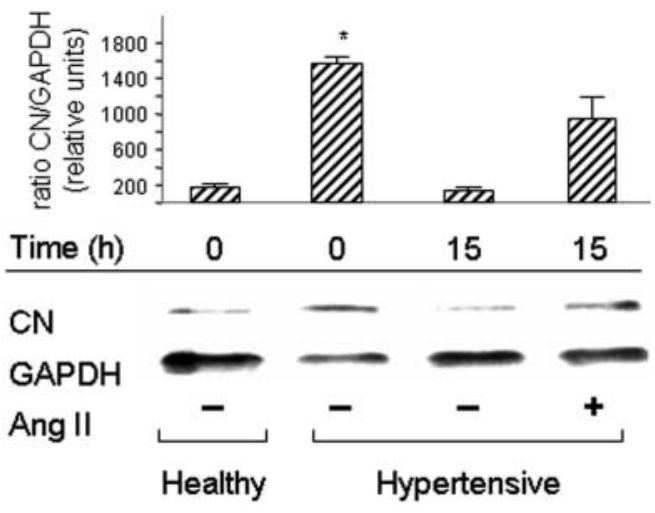

Figure 4 Levels of expression of $\mathrm{CN}$ in neutrophils of hypertensive patients and effect of Ang II on the expression of $\mathrm{CN}$ in these patients. Neutrophils from healthy subjects or hypertensive patients, as indicated, were cultured at $37^{\circ} \mathrm{C}$ in RPMI medium in the absence or presence of $100 \mathrm{nM}$ Ang II for $15 \mathrm{~h}$. The cells were then lysed and total protein levels of $\mathrm{CN}$ and GAPDH were analyzed by immunoblotting. The bands shown are representative of a set of three independent experiments. Plotted values (mean \pm s.E.M.) represent $\mathrm{CN}$ protein levels corrected for differences in GAPDH levels. Statistical significance: ${ }^{*} P<0 \cdot 01$, for hypertensive vs healthy.

\section{Implication of $\mathrm{CN}$ in oxidative stress in hypertension}

Hypertension is also characterized by an increased oxidative stress status (Drummond et al. 2011). In this context, HO1 is an inducible antioxidant enzyme that decreases the cellular levels of heme, a pro-oxidant group, and elevates those of bilirubin, an antioxidant (Gonzales et al. 2006). So, it is currently considered as a crucial enzyme to counteract intracellular oxidative stress. We have recently described that HO1 mRNA and protein expression becomes reduced together with its enzyme activity in human normal neutrophils on their treatment with Ang II (Alba et al. 2008). In this work, we set to investigate whether the downmodulatory action of Ang II on HO1 expression was mediated by $\mathrm{CN}$. With this purpose and because of the difficulty to use standard DNA transfection and microinjection techniques on neutrophils in vitro, as they are small, short-lived, and terminally differentiated cells (Haynes \& Fletcher 1990, Gaines et al. 2005), we used cyclosporine, a specific inhibitor of CN activity (O'Keefe et al. 1992, Ho et al. 1996). Cells thus were preincubated with CsA before subsequent treatment with Ang II and 15-deoxy$\Delta^{12,14}$-prostaglandin $\mathrm{J}_{2}\left(15 \mathrm{dPGJ}_{2}\right)$, the latter being a wellknown inducer of HO1 expression in human lymphocytes (Alvarez-Maqueda et al. 2004). Figure 6A shows that Ang II prevented induction of HO1 protein expression by $15 \mathrm{PGJ}_{2}$. However, this negative effect of Ang II was reversed when $\mathrm{CN}$ was previously inhibited with CsA.

HO1 expression becomes activated by pro-oxidant reagents via translocation to the nucleus of the transcription factor nuclear factor erythroid 2-related factor 2 (NRF2; Alam et al. 1999), which has emerged as a critical regulator of the cellular response to oxidative stress. In a previous work, we found that Ang II treatment before $15 \mathrm{dPGJ}_{2}$ addition significantly prevented nuclear accumulation of Nrf2 (Alba et al. 2008). We have now studied the possible participation of $\mathrm{CN}$ in NRF2 expression. As shown in Fig. 6B, it was interesting to observe that inhibition of $\mathrm{CN}$ also prevented the inhibition exerted by Ang II on the increase of Nrf2 nuclear levels. These results indicated that the negative effects exerted by Ang II on HO1 expression and Nrf2 nuclear levels in human neutrophils were mediated, at least in part, through $\mathrm{CN}$ activation.

Finally, we compared the capacity to express HO1 by neutrophils isolated from healthy subjects and hypertensive patients. Basal levels of HO1 protein were undetectable in cells from both sources (Fig. 7). However, when neutrophils were stimulated in vitro with $15 \mathrm{dPGJ}_{2}$, synthesis of $\mathrm{HO} 1$ was clearly detected, although it was noteworthy that its expression levels in the presence of the prostaglandin were markedly reduced in neutrophils isolated from hypertensive patients as compared with cells from healthy subjects. By contrast, when $\mathrm{CN}$ was inhibited by $\mathrm{CsA}$, HO1 expression was maximally induced by $15 \mathrm{dPGJ}_{2}$ in both groups.

\section{Discussion}

$\mathrm{CN}$ is a phosphatase implicated in signal transduction, whose function is particularly important in brain and lymphocytes and is susceptible to redox regulation. We have previously

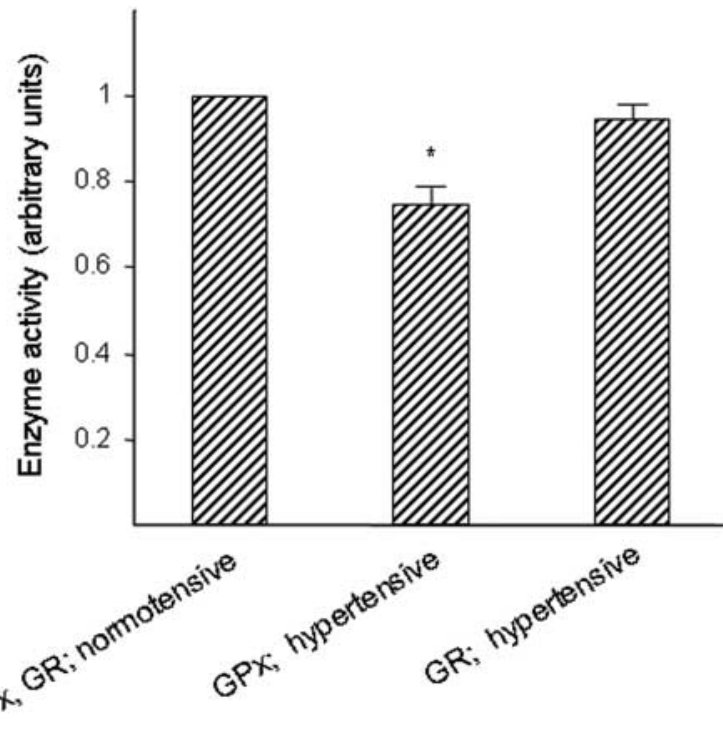

Figure 5 Effect of the hypertensive status on basal activity levels of GPx and GR in human neutrophils. Cells were lysed and extracts were used for the assay of GPX and GR enzyme activities as described in Materials and Methods sections. Values obtained in neutrophils from hypertensive patients are normalized to those from healthy donors and plotted as the mean \pm S.E.M. $(n=10)$. Statistical significance: ${ }^{*} P<0 \cdot 001$. 
A
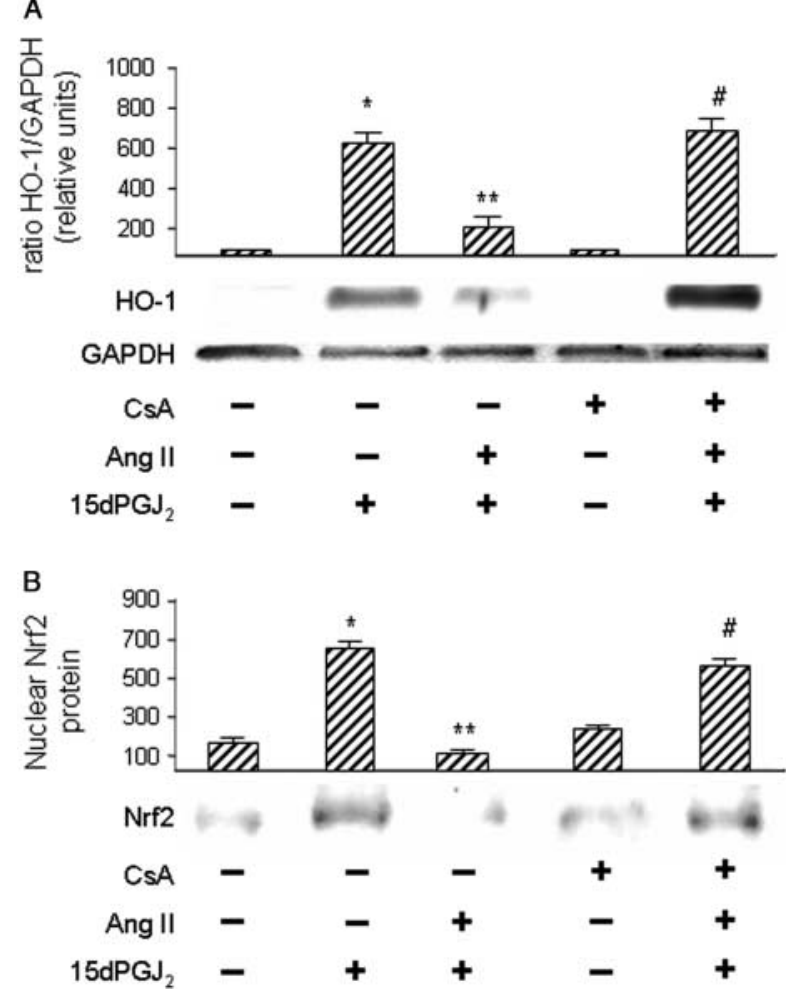

Figure 6 Effect of $\mathrm{CN}$ on negative modulation by Ang II of $\mathrm{HO} 1$ and Nrf2 nuclear translocation in human neutrophils. Neutrophils from healthy donors were grown at $37^{\circ} \mathrm{C}$ in RPMI medium in the absence or presence of $0.3 \mathrm{~g} / \mathrm{ml} \mathrm{CsA}$ for $1 \mathrm{~h}(\mathrm{~A})$ or $1 \mu \mathrm{g} / \mathrm{ml} \mathrm{CsA}$ for $30 \mathrm{~min}(\mathrm{~B})$. Then, $100 \mathrm{nM}$ Ang II was added for $1.5 \mathrm{~h}(\mathrm{~A})$ or $30 \mathrm{~min}(\mathrm{~B})$, and thereafter, the cells were stimulated or not with $10 \mu \mathrm{M} 15 \mathrm{dPG}_{2}$ for a further $5 \mathrm{~h}(\mathrm{~A})$ or $30 \mathrm{~min}(\mathrm{~B})$. The cells were then lysed and total proteins $(A)$ or nuclear extracts (B) were obtained. Levels of $\mathrm{HO} 1$, GAPDH (A), and NRF2 (B) proteins were measured by immunoblotting analysis. The bands shown are representative of a set of three independent experiments. Plotted values (mean \pm s.E.M.) represent total $\mathrm{HO} 1$ protein expression corrected for differences in GAPDH levels (A) or Nrf2 nuclear levels (B). Statistical significance: $* P<0 \cdot 01$, for $15 \mathrm{dPG}_{2}$-stimulated vs unstimulated; $* * P<0 \cdot 01$, for $15 \mathrm{dPG}_{2}$-stimulated, Ang II-treated vs Ang II-untreated; ${ }^{\sharp} P<0 \cdot 01$, for $15 \mathrm{dPGJ}_{2}$-stimulated, Ang II- and CsA-treated vs CsA-untreated.

described that $\mathrm{CN}$ is also present in neutrophils (Carballo et al. 1999), and that these cells are highly responsive to Ang II, a hormone that promotes the synthesis of superoxide anions and increases CN synthesis and activity (El Bekay et al. 2003). Present studies have been addressed to analyze whether CN activation promoted by Ang II in human neutrophils was modulated by the redox intracellular status.

Given that GSH is the main intracellular thiol implicated in the redox balance, we analyzed how depletion of GSH could affect the induction of CN by Ang II. With this purpose, we pretreated human neutrophils with BSX, a specific GSH synthesis inhibitor, before Ang II addition. We observed that depletion of intracellular GSH decreased the ability of Ang II to enhance $\mathrm{CN}$ activity and protein levels. We also investigated whether this inactivation was reversible and found that addition of GSH to neutrophils increased their $\mathrm{CN}$ activity.

It has been described that $\mathrm{CN}$ has 1-2 thiol groups essential for its full catalytic activity (Wagner \& Mutus 1991). Thus, the latter can be diminished on exclusion of reducing agents, such as GSH, and the reversal of $\mathrm{CN}$ inhibition exerted by BSX, after incubation with GSH, may be partially due to the ability of GSH to reduce thiols. Therefore, the intracellular levels of GSH seem to be critical for Ang II-promoted induction of $\mathrm{CN}$ expression and activity. Other authors have described similar increases in $\mathrm{CN}$ activity in fibroblasts on incubation with two other thiol-reducing agents, $\mathrm{N}$-acetylcysteine and lipoic acid (Sommer et al. 2000). The reversibility of CN inhibition by GSH is especially important in the emerging field of redox signaling. In general, reversibility is a major criterion for a particular enzyme modification to be associated with a physiological regulatory mechanism. The reversible oxidative modification of proteins, like formation of cysteine sulfenic acid or cyclic sulfenyl-amide (Salmeen et al. 2003), is opposed to nonspecific oxidative damage to proteins, such as protein carbonyl formation or cysteine oxidation to sulfonic acid (Droge 2002). Thus, rapid recovery of CN activity after removal of an oxidative signal indicates that $\mathrm{CN}$ redox regulation can participate in physiological signaling.

We have also checked the effects of another antioxidant, PDTC, on CN activity. However, when this compound was added to neutrophils before Ang II addition, CN activity was drastically canceled. This compound possesses antioxidative properties by the virtue of its ability to scavenge hydroxyl radicals and superoxide anions, as well as by chelating heavy

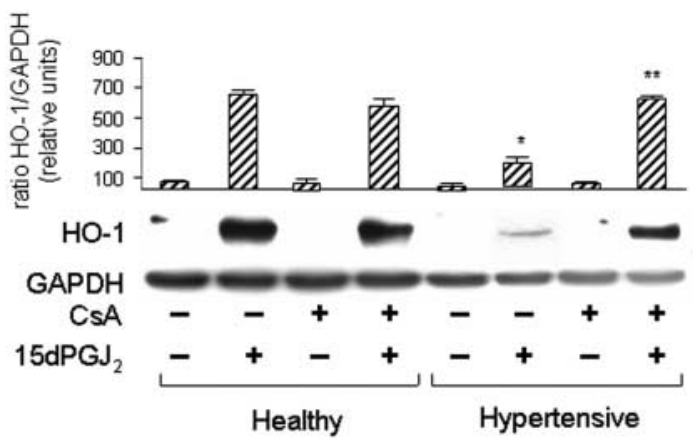

Figure $7 \mathrm{HO} 1$ expression levels in neutrophils of hypertensive patients and effect of CsA on the expression of HO1 in these patients. Neutrophils from healthy subjects or hypertensive patients were cultured at $37^{\circ} \mathrm{C}$ in RPMI medium in the absence or presence of CsA $(0.3 \mathrm{~g} / \mathrm{ml})$ for $1 \mathrm{~h}$ and then stimulated or not with $10 \mu \mathrm{M} 15 \mathrm{dPG}_{2}$ for further $15 \mathrm{~h}$. The cells were then lysed, total proteins were obtained, and HO1 and GAPDH levels were analyzed by immunoblotting. The bands shown are representative of a set of three independent experiments. Plotted values (mean \pm s.E.M.) represent $\mathrm{HO} 1$ protein expression levels corrected for differences in GAPDH levels. Statistical significance: $* P<0 \cdot 001$, for $15 \mathrm{dPGJ}_{2}$-stimulated in hypertensive vs $15 \mathrm{dPG}_{2}$-stimulated in healthy; ${ }^{* * P}<0 \cdot 001$, for $15 \mathrm{dPG}_{2}$-stimulated, CsA-treated vs $15 \mathrm{dPG}_{2}$-stimulated, and CsA-untreated in hypertensive. 
metals that can cause the production of hydroxyl radicals by catalyzing the Haber-Weiss reaction. Our results are in agreement with those reported by Sommer et al. (2000), who found that PDTC increased the activity of purified CN but inhibited most of the $\mathrm{CN}$ activity present in fibroblast lysates likely by chelating an exogenous metal(s) needed for its activity. By metal abstraction, PDTC inactivates copper/zinc superoxide dismutase (Kelner et al. 1989), a stabilizing factor in intact cells, which protects $\mathrm{CN}$ from inactivation (Wang et al. 1996). It has also been described that PDTC prevents activation of the transcription factor NF-AT in T cells, possibly by inhibiting $\mathrm{CN}$ phosphatase activity (Saccani et al. 1999).

$\mathrm{CN}$ belongs to the class of metallophosphatases containing iron and zinc in the binuclear center at their active site. Namgaladze et al. (2002) and Ghosh et al. (2003) have demonstrated that only under certain oxidation states in the dinuclear metal center of $\mathrm{CN}$ this enzyme retain catalytic activity. Indeed, $\mathrm{Fe}^{2+} / \mathrm{Zn}^{2+}$ is the active form of the enzyme with very high activity, and its oxidized $\mathrm{Fe}^{3+} / \mathrm{Zn}^{2+}$ form is the inactive form of the enzyme. Although, it was shown previously by $\mathrm{Yu}$ et al. (1997) that $\mathrm{Fe}^{3+} / \mathrm{Zn}^{2}$ was the active form of $\mathrm{CN}$.

Another approach used in the present work to expand current knowledge on regulation of CN by Ang II was based on the hypertension model, a status characterized by high levels of Ang II (Navar et al. 2011) and increased oxidative stress (Drummond et al. 2011). Besides, it is increasingly evident that the neutrophils are involved in this disease. This led us to address $\mathrm{CN}$ expression in neutrophils from normal and hypertensive subjects, where we obtained similar results. Next, by taking into account the importance of GSH for CN activity, we studied the activity of GPx and GR, two enzymes that modulate the intracellular levels of GSH, in neutrophils from normotensive and hypertensive subjects. This molecule has multiple roles both as an antioxidant and as a cosubstrate for the detoxification of peroxides by GPx. As a result of the action of this enzyme, GSH is oxidized to GSSG, the accumulation of which in tissues causes a variety of noxious effects. Therefore, GSSG must be reduced back to GSH in the reaction catalyzed by GR.

We found a highly significant decrease in GPx activity in neutrophils from hypertensive subjects and a slight, yet not significant, increase in GR activity. Similar results have been obtained in other cells and in animal models of hypertension (Gomez-Amores et al. 2006, 2007, Amirkhizi et al. 2010). In the hypertensive condition, the GSH/GSSG ratio is lower than in the healthy status (Gomez-Amores et al. 2006), probably due to associated oxidative stress. An explanation of GPx reduced activity may be that reactive aldehydes interact with the selenocysteine residue of GPx via a Michael-type addition reaction, resulting in the depletion of enzyme activity (Kondo et al. 2001). Another possibility may be a compensatory response by the hypertensive subjects to ameliorate GPx activity in order to maintain GSH levels.
In this sense, these levels of GSH in hypertensive subjects could be sufficient to maintain $\mathrm{CN}$ activity.

In the present work, we have also aimed at finding a possible functional implication for the high $\mathrm{CN}$ activity in hypertension. In recent years, endogenously produced $\mathrm{CO}$, released from heme by the activity of hemoxygenases, has been shown to exhibit vasoactive properties. These are constitutive (HO2) or inducible (HO1) isozymes able to catalyze the rate-limiting step in the metabolic conversion of pro-oxidant heme to endogenous antioxidants (biliverdin and bilirubin) and CO. HO1 expression is induced by a series of stimuli that have in common their ability to elicit oxidative stress and exhibit anti-inflammatory, anti-proliferative, antiapoptotic, and antioxidant effects on the vasculature, in addition to protecting against atherosclerosis development (Loboda et al. 2008).

Our group has previously shown that HO1 synthesis is induced by $15 \mathrm{dPGJ}_{2}$ in neutrophils, and that HO1 expression (at the mRNA and protein levels) and activity are downregulated in both neutrophils from healthy subjects treated with Ang II and in untreated neutrophils from hypertensive patients (Alba et al. 2008). As Ang II is able to induce both $\mathrm{CN}$ synthesis and activity in human neutrophils, we have examined in this work the possibility that the Ang II effect observed on HO1 might be mediated by CN. We found that inhibition of $\mathrm{CN}$ by CsA did abolish the effect of Ang II on HO1 synthesis, which allowed us to infer that Ang II exerts its effect on HO1 expression in a $\mathrm{CN}$-mediated fashion. It is noteworthy that results similar to those found in Ang II-treated neutrophils were obtained in cells from hypertensive patients. The expression of HO1 and/ or the application of exogenous $\mathrm{CO}$ have been shown to confer protection in several models of cardiovascular injury or disease, including hypertension and atherosclerosis, and in HO1 deficiency it has been related to extensive endothelial damage (Ryter et al. 2006).

The main transcription factor responsible for HO1 synthesis is NRF2. When $\mathrm{CN}$ was inhibited by CsA, a decrease in Nrf2 nuclear translocation was found in this work. We can thus infer that $\mathrm{CN}$ prevents $\mathrm{HO} 1$ induction by decreasing the translocation to the nucleus of the transcription factor NRF2. The regulation of NRF2 is currently an issue of great interest. It has been proposed that the Nrf2 system may be a potential target for the development of indirect antioxidants aimed at the prevention/treatment of a wide array of human diseases (Jung \& Kwak 2010). Dissociation of Nrf2 from Keap1 is the primary mechanism for Nrf2 translocation. The increase in the cellular oxidative status provokes the disruption of Nrf2-Keap1 interaction and thereby increases nuclear translocation of Nrf2. It has been demonstrated that inducers of NRF2-dependent transcription inhibit Keap1-dependent Nrf2 degradation exerted by the ubiquitin-proteasome pathway (Zhang \& Hannink 2003). In mouse peritoneal macrophage cells an electrophilic agent, diethylmaleate, has been shown to facilitate nuclear accumulation of $\mathrm{Nrf} 2$ by suppressing 
Keap1 activity (Itoh et al. 2003). How CN may hinder Nrf2 nuclear translocation in our neutrophil preparations is unknown. It can be speculated that $\mathrm{CN}$ might affect the redox status of Keap 1 and thereby decrease its dissociation from Nrf2 or promote its degradation.

Finally, we have also compared the capacity to express HO1 by neutrophils isolated from healthy subjects and hypertensive patients. HO1 expression in the presence of the inducer $15 \mathrm{dPGJ}_{2}$ was markedly lower in neutrophils obtained from hypertensive patients than in cells from healthy subjects. When $\mathrm{CN}$ was inhibited with CsA, HO1 expression was established in both groups.

In summary, the intracellular redox status of neutrophils is highly critical for Ang II-mediated induction of CN activity. These results support and extend our previous results and those of other authors on the modulation of CN activity by redox factors and its implication in the hypertension status.

\section{Declaration of interest}

The authors declare that there is no conflict of interest that could be perceived as prejudicing the impartiality of the research reported.

\section{Funding}

G A was supported by fellowships from the Ministerio de Educación y Ciencia (BFU2006-13802) and the Consejería de Innovación, Ciencia y Empresa, Junta de Andalucía (P08-CVI-03550). M E R-Q was supported by a fellowship from the Asociación Virgen Macarena, Hospital Universitario Virgen Macarena, Sevilla. This work was funded by grants from the Consejería de Innovación, Ciencia y Empresa, Junta de Andalucía (P06-CTS-01936 and P08-CVI-03550) to F S, and from the Consejería de Salud, Junta de Andalucía (CS 0116/2007) to E P.

\section{Acknowledgement}

Thanks to Margarita Rodríguez Borrego for her technical assistance.

\section{References}

Alam J, Stewart D, Touchard C, Boinapally S, Choi AM \& Cook JL 1999 $\mathrm{Nrf2}$, a cap'n'collar transcription factor, regulates induction of the heme oxygenase-1 gene. Journal of Biological Chemistry 274 26071-26078. (doi:10.1074/jbc.274.37.26071)

Alba G, El Bekay R, Chacon P, Reyes ME, Ramos E, Olivan J, Jimenez J, Lopez JM, Martin-Nieto J, Pintado E et al. 2008 Heme oxygenase-1 expression is down-regulated by angiotensin II and under hypertension in human neutrophils. Journal of Leukocyte Biology 84 397-405. (doi:10.1189/ jlb.0108035)

Alvarez-Maqueda M, El Bekay R, Alba G, Monteseirin J, Chacon P, Vega A, Martin-Nieto J, Bedoya FJ, Pintado E \& Sobrino F 2004 15-Deoxy- $\Delta^{12,14}$ prostaglandin $\mathrm{J}_{2}$ induces heme oxygenase- 1 gene expression in a reactive oxygen species-dependent manner in human lymphocytes. Journal of Biological Chemistry 279 21929-21937. (doi:10.1074/jbc.M400492200)

Amirkhizi F, Siassi F, Djalali M \& Foroushani AR 2010 Assessment of antioxidant enzyme activities in erythrocytes of pre-hypertensive and hypertensive women. Journal of Research in Medical Sciences 15 270-278.
Aperia A, Ibarra F, Svensson LB, Klee C \& Greengard P 1992 Calcineurin mediates alpha-adrenergic stimulation of $\mathrm{Na}^{+}, \mathrm{K}(+)$-ATPase activity in renal tubule cells. PNAS 89 7394-7397. (doi:10.1073/pnas.89.16.7394)

Carballo M, Marquez G, Conde M, Martín-Nieto J, Monteseirin J, Conde J, Pintado E \& Sobrino F 1999 Characterization of calcineurin in human neutrophils. Inhibitory effect of hydrogen peroxide on its enzyme activity and on NF-KB DNA binding. Journal of Biological Chemistry 274 93-100. (doi:10.1074/jbc.274.1.93)

Carlberg I \& Mannervik B 1975 Purification and characterization of the flavoenzyme glutathione reductase from rat liver. Journal of Biological Chemistry 250 5475-5480.

Cuzzocrea S, Zingarelli B, O'Connor M, Salzman AL \& Szabo C 1998 Effect of L-buthionine-(S,R)-sulphoximine, an inhibitor of $\gamma$-glutamylcysteine synthetase on peroxynitrite- and endotoxic shock-induced vascular failure. British Journal of Pharmacology 123 525-537. (doi:10.1038/sj.bjp.0701612)

Droge W 2002 Free radicals in the physiological control of cell function. Physiological Reviews 82 47-95. (doi:10.1152/physrev.00018.2001)

Drummond GR, Selemidis S, Griendling KK \& Sobey CG 2011 Combating oxidative stress in vascular disease: NADPH oxidases as therapeutic targets. Nature Reviews. Drug Discovery 10 453-471. (doi:10.1038/nrd3403)

El Bekay R, Alvarez M, Monteseirin J, Alba G, Chacon P, Vega A, Martín-Nieto J, Jimenez J, Pintado E, Bedoya FJ et al. 2003 Oxidative stress is a critical mediator of the angiotensin II signal in human neutrophils: involvement of mitogen-activated protein kinase, calcineurin, and the transcription factor NF-KB. Blood 102 662-671. (doi:10.1182/blood-2002-09-2785)

Finkel T 2011 Signal transduction by reactive oxygen species. Journal of Cell Biology 194 7-15. (doi:10.1083/jcb.201102095)

Gaines P, Chi J \& Berliner N 2005 Heterogeneity of functional responses in differentiated myeloid cell lines reveals EPRO cells as a valid model of murine neutrophil functional activation. Journal of Leukocyte Biology 77 669-679. (doi:10.1189/jlb.1004567)

Ghosh MC, Wang X, Li S \& Klee C 2003 Regulation of calcineurin by oxidative stress. Methods in Enzymology 366 289-304.

Gilbert C, Rollet-Labelle E \& Naccache PH 2002 Preservation of the pattern of tyrosine phosphorylation in human neutrophil lysates. II. A sequential lysis protocol for the analysis of tyrosine phosphorylation-dependent signalling. Journal of Immunological Methods 261 85-101. (doi:10.1016/ S0022-1759(01)00553-1)

Gomez-Amores L, Mate A, Revilla E, Santa-Maria C \& Vazquez CM 2006 Antioxidant activity of propionyl-L-carnitine in liver and heart of spontaneously hypertensive rats. Life Sciences 78 1945-1952. (doi:10.1016/j. lfs.2005.08.023)

Gomez-Amores L, Mate A, Miguel-Carrasco JL, Jimenez L, Jos A, Camean AM, Revilla E, Santa-Maria C \& Vazquez CM 2007 L-carnitine attenuates oxidative stress in hypertensive rats. Journal of Nutritional Biochemistry 18 533-540. (doi:10.1016/j.jnutbio.2006.10.004)

Gonzales S, Perez MJ, Perazzo JC \& Tomaro ML 2006 Antioxidant role of heme oxygenase- 1 in prehepatic portal hypertensive rats. World Journal of Gastroenterology 12 4149-4155.

Gualberto A, Marquez G, Carballo M, Youngblood GL, Hunt SW III, Baldwin AS \& Sobrino F 1998 p53 transactivation of the HIV-1 long terminal repeat is blocked by PD 144795, a calcineurin-inhibitor with anti-HIV properties. Journal of Biological Chemistry 273 7088-7093. (doi:10.1074/jbc.273.12.7088)

Haynes AP \& Fletcher J 1990 Neutrophil function tests. Bailliere's Clinical Haematology 3 871-887. (doi:10.1016/S0950-3536(05)80139-8)

Hissin PJ \& Hilf R 1976 A fluorometric method for determination of oxidized and reduced glutathione in tissues. Analytical Biochemistry 74 214-226. (doi:10.1016/0003-2697(76)90326-2)

Ho S, Clipstone N, Timmermann L, Northrop J, Graef I, Fiorentino D, Nourse J \& Crabtree GR 1996 The mechanism of action of cyclosporin A and FK506. Clinical Immunology and Immunopathology 80 S40-S45. (doi:10.1006/clin.1996.0140)

Itoh K, Wakabayashi N, Katoh Y, Ishii T, O'Connor T \& Yamamoto M 2003 Keap1 regulates both cytoplasmic-nuclear shuttling and degradation of Nrf2 in response to electrophiles. Genes to Cells 8 379-391. (doi:10.1046/ j.1365-2443.2003.00640.x) 
Jung KA \& Kwak MK 2010 The Nrf2 system as a potential target for the development of indirect antioxidants. Molecules 15 7266-7291. (doi:10.3390/molecules15107266)

Kelner MJ, Bagnell R, Hale B \& Alexander NM 1989 Inactivation of intracellular copper-zinc superoxide dismutase by copper chelating agents without glutathione depletion and methemoglobin formation. Free Radical Biology \& Medicine 6 355-360. (doi:10.1016/0891-5849(89)90079-8)

Kondo M, Oya-Ito T, Kumagai T, Osawa T \& Uchida K 2001 Cyclopentenone prostaglandins as potential inducers of intracellular oxidative stress. Journal of Biological Chemistry 276 12076-12083. (doi:10.1074/jbc.M009630200)

Lawrence RA \& Burk RF 1976 Glutathione peroxidase activity in seleniumdeficient rat liver. Biochemical and Biophysical Research Communications 71 952-958. (doi:10.1016/0006-291X(76)90747-6)

Lawrence MC, Naziruddin B, Levy MF, Jackson A \& McGlynn K 2011 Calcineurin/nuclear factor of activated $T$ cells and MAPK signaling induce TNF-\{alpha $\}$ gene expression in pancreatic islet endocrine cells. Journal of Biological Chemistry 286 1025-1036. (doi:10.1074/jbc.M110.158675)

Loboda A, Jazwa A, Grochot-Przeczek A, Rutkowski AJ, Cisowski J, Agarwal A, Jozkowicz A \& Dulak J 2008 Heme oxygenase-1 and the vascular bed: from molecular mechanisms to therapeutic opportunities. Antioxidants \& Redox Signaling 10 1767-1812. (doi:10.1089/ars.2008.2043)

Namgaladze D, Hofer HW \& Ullrich V 2002 Redox control of calcineurin by targeting the binuclear $\mathrm{Fe}(2+)-\mathrm{Zn}(2+)$ center at the enzyme active site. Journal of Biological Chemistry 277 5962-5969. (doi:10.1074/jbc. M111268200)

Nataraj C, Oliverio MI, Mannon RB, Mannon PJ, Audoly LP, Amuchastegui CS, Ruiz P, Smithies O \& Coffman TM 1999 Angiotensin II regulates cellular immune responses through a calcineurin-dependent pathway. Journal of Clinical Investigation 104 1693-1701. (doi:10.1172/ JCI7451)

Navar LG, Prieto MC, Satou R \& Kobori H 2011 Intrarenal angiotensin II and its contribution to the genesis of chronic hypertension. Current Opinion in Pharmacology 11 180-186. (doi:10.1016/j.coph.2011.01.009)

O'Keefe SJ, Tamura J, Kincaid RL, Tocci MJ \& O’Neill EA 1992 FK-506and CsA-sensitive activation of the interleukin-2 promoter by calcineurin. Nature 357 692-694. (doi:10.1038/357692a0)

Paravicini TM \& Touyz RM 2006 Redox signaling in hypertension. Cardiovascular Research 71 247-258. (doi:10.1016/j.cardiores.2006.05.001)

Rusnak F \& Mertz P 2000 Calcineurin: form and function. Physiological Reviews 80 1483-1521.

Ryter SW, Alam J \& Choi AM 2006 Heme oxygenase-1/carbon monoxide: from basic science to therapeutic applications. Physiological Reviews $\mathbf{8 6}$ 583-650. (doi:10.1152/physrev.00011.2005)
Saccani S, Saccani A, Varesio L, Ghosh P, Young HA \& Sica A 1999 Divergent effects of dithiocarbamates on AP-1-containing and AP-1-less NFAT sites. European Journal of Immunology 29 1194-1201. (doi:10.1002/(SICI)15214141(199904)29:04 < 1194::AID-IMMU1194>3.0.CO;2-0)

Salmeen A, Andersen JN, Myers MP, Meng TC, Hinks JA, Tonks NK \& Barford D 2003 Redox regulation of protein tyrosine phosphatase 1B involves a sulphenyl-amide intermediate. Nature 423 769-773. (doi:10.1038/nature01680)

Segel GB, Halterman MW \& Lichtman MA 2011 The paradox of the neutrophil's role in tissue injury. Journal of Lenkocyte Biology 89 359-372. (doi:10.1189/jlb.0910538)

Sela S, Mazor R, Amsalam M, Yagil C, Yagil Y \& Kristal B 2004 Primed polymorphonuclear leukocytes, oxidative stress, and inflammation antecede hypertension in the Sabra rat. Hypertension 44 764-769. (doi:10.1161/01. HYP.0000144480.10207.34)

Sommer D, Fakata KL, Swanson SA \& Stemmer PM 2000 Modulation of the phosphatase activity of calcineurin by oxidants and antioxidants in vitro. European Journal of Biochemistry/FEBS 267 2312-2322. (doi:10.1046/ j.1432-1327.2000.01240.x)

Tsukimori K, Nakano H \& Wake N 2007 Difference in neutrophil superoxide generation during pregnancy between preeclampsia and essential hypertension. Hypertension 49 1436-1441. (doi:10.1161/HYPERTENSIONAHA.106.086751)

Wagner J \& Mutus B 1991 Transient activation of calcineurin during thiol modification. Second Messengers and Phosphoproteins 13 199-215.

Wang X, Culotta VC \& Klee CB 1996 Superoxide dismutase protects calcineurin from inactivation. Nature 383 434-437. (doi:10.1038/ $383434 \mathrm{a} 0)$

Yu L, Golbeck J, Yao J \& Rusnak F 1997 Spectroscopic and enzymatic characterization of the active site dinuclear metal center of calcineurin: implications for a mechanistic role. Biochemistry 36 10727-10734. (doi:10.1021/bi970519g)

Zhang DD \& Hannink M 2003 Distinct cysteine residues in Keap1 are required for Keap1-dependent ubiquitination of Nrf2 and for stabilization of Nrf2 by chemopreventive agents and oxidative stress. Molecular and Cellular Biology 23 8137-8151. (doi:10.1128/MCB.23.22.8137-8151. 2003)

Received in final form 21 June 2012

Accepted 27 June 2012

Made available online as an Accepted Preprint 27 June 2012 